\title{
Social and geographical inequalities in the choice of foot therapy as preventive care: A nationwide registry study on Danish people with diabetes
}

\author{
CHRISTINE MARIE BÆKØ HALLING ${ }^{1}{ }^{*}$ \\ JACOB LADENBURG $^{2}$ \\ ${ }^{1}$ VIVE - the Danish Center for Social Science Research, Denmark \\ ${ }^{2}$ The ROCKWOOL Foundation Research Unit, Denmark
}

\begin{abstract}
Diabetic foot ulcers are a serious complication of diabetes with high costs and adverse sequelae, such as lower-extremity amputations. International guidelines recommend that all people with diabetes should have their feet inspected at least once a year. This study is aimed at determining whether socioeconomic factors influence the probability of having the feet inspected by a chiropodist on a nationally representative sample of people with diabetes. We estimate a logit model for the choice determinants of foot inspections among people with diabetes. Of all people with diabetes, $73 \%$ have not had their feet inspected by a chiropodist. The results indicate social and geographical inequality with regard to diabetic foot care. Especially for ethnic minorities, people with low income and people living in rural and remote areas. The findings are robust to a series of sensitivity analyses.
\end{abstract}

JEL classification: D01, I11, I14

Key words: opportunity costs, inequalities; socioeconomic factors, foot care, diabetes

\section{Introduction}

Today, diabetes is a major public health problem in terms of financial and social consequences, and its magnitude is predicted to grow rapidly in the future (Carstensen et al., 2008; King et al., 1998; Nita et al., 1992; Sorts $\varnothing$ et al., 2016). Diabetes is not only associated with a massive economic burden but also mortality and reduced quality of life. In Europe, it is estimated that more than 600 thousand people with diabetes died during 2015 (IDF, 2015) and that many more have serious complications due to their diabetes. Diabetic foot ulcers is one of these serious complications of diabetes and are associated with high costs and potential adverse complications (Armstrong et al., 1998; Boulton et al., 2005; Danish Health Authority, 2011). Studies show that 25-28\% of foot ulcers may result in lower-extremity amputations and of these $50 \%$ lead to death within five years (Armstrong et al., 1998; Danish Health Authority, 2011). The costs of healing a diabetic foot are estimated to be EUR 21-34,000 in Denmark (Kruse \& Nørregaard, 2012). When an amputation is subsequently performed, the costs are estimated to increase to EUR 5580,000. Kruse \& Nørregaard (2012) highlight- the need for effective strategies to prevent or reduce diabetic foot ulcer complications.

* Correspondence to: Christine Marie Bækø Halling, VIVE - the Danish Center for Social Science Research, Herluf Trolles Gade 11, 1052 København K, Denmark. E-mail: cmskovgaard@gmail.com.

Published: Online September 2019. dx.doi.org/10.5617/njhe.5914 
International guidelines on the prevention of foot problems in diabetes recommend that all people with diabetes should have their feet examined at least once a year (Schaper et al., 2017). Studies have shown that regular foot inspections can reduce the incidence of foot ulcers and the number of amputations (Boulton et al., 2005; Cavanagh et al., 2005; Edmonds, 1999; Lavery et al., 2005; Lavery et al., 2010). For example, a randomized controlled study from 2003 suggests that regular preventive care by a chiropodist may reduce recurrence of foot ulcers among diabetic patients (Plank et al., 2003). Another example is an American study showing a 47\% decrease in amputations after implementation of preventive initiatives (e.g. podiatry) (Lavert et al., 2005). Despite the importance of foot examination at least once per year and the potential severe complications, personal costs and costs to society, surprisingly little knowledge exists about who has their feet inspected by a chiropodists and whether there is systematic variation in the inspection propensity among different sociodemographic groups. Identification of such variations would be of significant importance in order to implement actions to alleviate the differences. The existing literature is often limited by small sample sizes. For example, Mirmiran et al. (2000) examined 392 people, whereof $22 \%$ did not have their feet examined by any health care provider. Another problem in the literature is the use of selected samples. Gibson et al. (2014), who estimated the effect of foot therapy through matching among people with health insurance. Their model includes almost 50,000 persons with insurance through their workplace, making the analysis biased towards people with work-paid insurance. They do not consider the weakest population groups, who also are associated with large societal costs in the Nordic welfare systems with free access to treatments. Moreover, some studies consider surveys of people with diabetes' knowledge of foot therapy (George et al., 2013; Pollock et al., 2004) and the effect of foot therapy on amputations and foot-related admissions (Cavanagh et al., 2005; Edmonds, 1999; Lavery et al., 2005). A study from 2010 uses a survey to examine the socioeconomic differences in people with diabetes with or without foot-problems. However, the study does not investigate who is trying to prevent the problems (Nather et al., 2010).

Using a 100\% registry of all diagnosed Danish individuals with diabetes (321,075 persons), we estimate the propensity to have your feet examined by a subsidised chiropodist at least once per year. The subsidy alleviated cost of visiting a chiropodist is EUR 25. The data gives a unique opportunity to obtain credible insights into who follows the recommendation to have their feet by a chiropodist inspected at least annually and who does not. Our contribution to the literature is a significantly larger number of included individuals and an unselected population, as we include the entire population of people diagnosed with diabetes.

The objective of this study is therefore to obtain knowledge on which socioeconomic factors that influence people with diabetes to have an annual diabetic foot inspection by a chiropodist. In order to be able to reduce health inequalities in relation to preventive foot therapy and thus possibly prevent costly treatments in the health system in general, it is important to understand systematic differences in who have their feet inspected annually. If we can identify the groups of people who do not follow the recommendations, then we can potentially identify effective strategies to convince people into taking better care of their feet.

\subsection{A theoretical approach}

In a classical lifecycle-investment framework, health behaviour, such as time spent on having your feet examined by a chiropodist, can be viewed as an investment in health capital. Grossman (1972) was the first to formulate a theory on investments in health capital. 
Together with Becker's (1965) theory of allocation of time, according to which individuals are seen as producers and not only consumers of goods, a theory of opportunity costs appeared. The influence of opportunity costs on health behaviour has previously been discussed in the literature. It has been argued, for instance, that future opportunity costs may play a role in health behaviour that has significant future consequences for the ability to work and thus future income (Cowell, 2006). Another example is Cutler et al. (2003), who concludes that reduced time spent on food preparation can in part explain the increasing obesity rates in the US.

Our focus is to empirically test, which people with diabetes that invest time in having their feet examined by a chiropodist annually, which do not. We do that by regressing the visit to a chiropodist as a function of a range of sociodemographic variables, such as gender, age, income, education, marital status and ethnicity. The inclusion of the latter is inspired by the findings of Ettner et al. (2009) and Priebe et al. (2011). They find differences in knowledge of health treatment and self-production of health care between ethnic groups. We also include urban/rural variables to test if access to chiropodist care influence the propensity to have been at a chiropodist. Finally, we include information on the number of years since the individuals were diagnosed with diabetes.

\subsection{Data}

The study is based on the National Diabetes Registry in 2012, which identifies the majority of all people with diabetes in Denmark based on administrative registries (Carstensen et al., 1998; Carstensen et al., 2011; Green et al., 2015). In total, 321,075 people with diabetes were identified in 2012. The information on the publicly supported service of foot therapy for people with diabetes is from the National Health Insurance Service Registry (registered with the code 54). The registry data include all diabetic foot-related consultations, including preventive (i.e. individual insoles and orthotics) and trimming treatments (i.e. removing calluses) or foot ulcer treatment (i.e. wound care) ${ }^{1}$. A common feature is that all diabetesrelated consultations involve a foot inspection. In the analyses, we soley focus on preventive visits and trimming treatments. The reason is that we do not have data on, which people with diabetes who have footulcer or not. Without this information, we cannot exclude all those people with diabetes who do not have footulcer and thereby control for selection. In the analysis, we join the data on preventive treatment and trimming treatment in the analyses. The reason is that feet inspection is carried out on both treatments and that a clear distinction in registation between trimming and feet inspection is not established on chiropodist level. Often a feet inspection will include some type of trimming, but is not recorded as a specific trimming treatment in the register ${ }^{2}$.

Via the national registry data, we have access to a wide range of socioeconomic data, such as age, gender, marital status, income, education and ethnic background. Furthermore, information on the municipality of residence is used to calculate an urbanisation index, which is divided into the following four categories based on parishes (Ministry of Housing, Urban and Rural Affairs, 2013): urban areas close to the largest cities (urban areas), urban areas further away form the largest cities (intermediate urban areas), rural areas close to the largest cities (rural areas), and rural areas further away from the largest cities and small islands (remote areas).

\footnotetext{
${ }^{1}$ The specific codes in the registry are as follows. Preventive: 542150, 542151, 542152, 542153, 542154, 542155, 542156 and 542157. Trimming: 542172, 542173 and 542174. Foot ulcer treatment: 542175 and 542176

2 The arguments put forward are based on consultations with the Danish Union of Chiropodist.
} 


\subsection{Statistical analyses}

This study is a cross-sectional study based on data from 2012. Multiple logistic regressions were used to estimate significant $(\mathrm{p}<0.05)$ differences in socioeconomic and geographical factors between the two cohorts of diabetic patients - one with and the other without a diabetes-related visit to a chiropodist during that year. Included as explanatory variables are gender, age, income (divided into quartiles), education (divided into basic school, vocational education, short-cycle higher education, medium-cycle higher education and long-cycle higher education), marital status (divided into living alone, married/cohabiting and other), urban index, ethnic background (Danish, immigrants from Western countries and immigrants from non-Western countries) and time since diabetes diagnosis. Thus, both general variables, such as gender and age, and variables indicating socioeconomic status are included. We suspected that income did not have a linear relationship with the use of podiatry, which is why we divided income into quartiles (categorical variable). This assumption did not change the estimates or significance compared to the estimates, when performing a spline analysis (not shown). The time since diabetes diagnosis is divided into three categories; 0-4 years ago, 5-10 years ago and more than 10 years ago. Each group contains almost a third of the people included.

The statistical analysis was carried out using SAS 9.4 and Stata 14. Since we are working with sensitive personal data, the analyses are performed on Statistic Denmark's servers, where all persons are anonymised and the data accessibility requires an individual research application.

\section{Results}

\subsection{Descriptive results}

In total 321,075 people were identified with diabetes in Denmark in 2012. A person having one of the six following criteria in the Danish health registries in the years 1972-2012 is defined as having diabetes in 2012. The criteria are 1) had at least five blood glucose measurements within a period of 365 days, 2) had an hospital admission with diabetes as diagnosis, 3) used the service of "foot therapy for patients with diabetes", 4) redeemed two prescriptions for insulin within a period of six months, and 5) had at least two blood glucose measurements per year over a five year period. Classification of type 1 and type 2 diabetes is not possible based on the registry data. However, for this analysis the classification is not needed, as foot therapy is relevant for both types of diabetes.

Table 1 shows the number of people with diabetes distributed by age, gender and other socioeconomic variables included in the subsequent analyses. The distribution for the whole Danish population is shown as benchmark. The distribution of men and women is fairly even, and as expected the group of people with diabetes is older than the general population. The level of education is lower and the proportion of people living alone is higher than in the population as a whole. This may be related to the fact that people with diabetes are older. People with diabetes primarily live in the urban areas. However, the distribution is not markedly different from that of the rest of the Danish population. Among the people with diabetes in the sample $27 \%$ of people with diabetes have been to a publicly subsidised chiropodist.

\subsection{Average results}

Regression results for having your feet inspected annually are shown in Table 2 . The results are shown as estimated marginal effects. If all groups had the same propensity to have their 
feet inspected by a chiropodist, all results in the regression should be insignificant, as we are measuring differences between the groups defined by the chosen variables. However, almost all variables are significant.

Table 1: Descriptive statistics for people with diabetes compared with the Danish population, $2012(\mathrm{~N}=321,075)$

\begin{tabular}{|c|c|c|c|c|}
\hline & & $\begin{array}{l}\text { Number of } \\
\text { people with } \\
\text { diabetes }\end{array}$ & $\%$ of total & $\begin{array}{l}\% \text { in the Danish } \\
\text { population }\end{array}$ \\
\hline \multicolumn{5}{|l|}{ Gender } \\
\hline & Men & 165,389 & $52 \%$ & $49.6 \%$ \\
\hline & Women & 155,686 & $48 \%$ & $50.4 \%$ \\
\hline \multicolumn{5}{|l|}{ Age } \\
\hline & $0-39$ years & 22,036 & $7 \%$ & $49 \%$ \\
\hline & $40-49$ years & 31,080 & $10 \%$ & $15 \%$ \\
\hline & $50-59$ years & 55,332 & $17 \%$ & $13 \%$ \\
\hline & $60-69$ years & 91,242 & $28 \%$ & $12 \%$ \\
\hline & 70-79 years & 76,871 & $24 \%$ & $7 \%$ \\
\hline & $80+$ years & 44,514 & $14 \%$ & $4 \%$ \\
\hline \multicolumn{5}{|c|}{ Education } \\
\hline & Basic school & 132,342 & $41 \%$ & $29 \%$ \\
\hline & Vocational education & 123,098 & $38 \%$ & $40 \%$ \\
\hline & Short-cycle higher education & 9,583 & $3 \%$ & $4 \%$ \\
\hline & $\begin{array}{l}\text { Medium-cycle higher } \\
\text { education }\end{array}$ & 31,421 & $10 \%$ & $15 \%$ \\
\hline & $\begin{array}{l}\text { Long-cycle higher and } \\
\text { research education }\end{array}$ & 10,883 & $3 \%$ & $7 \%$ \\
\hline & Missing & 13,748 & $4 \%$ & $4 \%$ \\
\hline \multicolumn{5}{|c|}{ Marital status } \\
\hline & Living alone & 115,556 & $36 \%$ & $28 \%$ \\
\hline & Married/cohabiting & 177,371 & $55 \%$ & $60 \%$ \\
\hline & Other & 28,148 & $9 \%$ & $13 \%$ \\
\hline \multicolumn{5}{|c|}{ Urban index (based on parishes)* } \\
\hline & Urban areas & 177,469 & $55 \%$ & $59 \%$ \\
\hline & Intermediate urban areas & 52,311 & $16 \%$ & $14 \%$ \\
\hline & Rural areas & 38,602 & $12 \%$ & $13 \%$ \\
\hline & Remote areas & 52,307 & $16 \%$ & $14 \%$ \\
\hline \multicolumn{5}{|c|}{ Ethnic background } \\
\hline & Danish & 289,415 & $90.1 \%$ & $89.6 \%$ \\
\hline & From a Western country & 7,999 & $2.5 \%$ & $3.6 \%$ \\
\hline & From a non-Western country & 23,661 & $7.4 \%$ & $6.8 \%$ \\
\hline \multicolumn{5}{|c|}{ Received diabetes-related podiatry ** } \\
\hline & No visits to a chiropodist & 231,232 & $73 \%$ & - \\
\hline & $\begin{array}{l}\text { At least one visit to a } \\
\text { chiropodist }\end{array}$ & 87,078 & $27 \%$ & - \\
\hline
\end{tabular}


Table 2: Logistic regression on the use of publicly supported foot therapy 2012, marginal effects

\begin{tabular}{|c|c|}
\hline & $\begin{array}{l}\text { Preventive treatment } \\
\text { (yes/no) }\end{array}$ \\
\hline \multicolumn{2}{|l|}{ Years since diagnosis in registry (Reference: 0-4 years) } \\
\hline $5-10$ years & $\begin{array}{l}0.0311^{* * *} \\
(0.00180)\end{array}$ \\
\hline More than 10 years & $\begin{array}{l}0.145^{* * *} \\
(0.00196)\end{array}$ \\
\hline Women (Reference: men) & $\begin{array}{l}0.00628 * * * \\
(0.00163)\end{array}$ \\
\hline \multicolumn{2}{|l|}{ Income quartiles (Reference: $\mathbf{1}^{\text {st }}$ quartile) } \\
\hline $2^{\text {nd }}$ income quartile & $\begin{array}{l}0.0274 * * * \\
(0.00255)\end{array}$ \\
\hline $3^{\text {rd }}$ income quartile & $\begin{array}{l}0.0299 * * * \\
(0.00239)\end{array}$ \\
\hline $4^{\text {th }}$ income quartile & $\begin{array}{l}0.0110 * * * \\
(0.00256)\end{array}$ \\
\hline Age & $\begin{array}{l}0.00440 * * * \\
(6.29 \mathrm{e}-05)\end{array}$ \\
\hline \multicolumn{2}{|l|}{ Education (Reference: basic school) } \\
\hline Vocational education & $\begin{array}{l}0.00456^{* *} \\
(0.00185)\end{array}$ \\
\hline Short-cycle higher education & $\begin{array}{l}-0.00257 \\
(0.00491)\end{array}$ \\
\hline Medium-cycle higher education & $\begin{array}{l}-0.0162 * * * \\
(0.00293)\end{array}$ \\
\hline Long-cycle higher education & $\begin{array}{l}-0.0633 * * * \\
(0.00431)\end{array}$ \\
\hline Unknown & $\begin{array}{l}-0.0724 * * * \\
(0.00386)\end{array}$ \\
\hline \multicolumn{2}{|l|}{ Marital status (Reference: living alone) } \\
\hline Other & $\begin{array}{l}-0.00644^{* *} \\
(0.00318)\end{array}$ \\
\hline Married/cohabiting & $\begin{array}{l}0.0208 * * * \\
(0.00191)\end{array}$ \\
\hline \multicolumn{2}{|l|}{ Urban index, based on parishes (Reference: Urban areas) } \\
\hline Intermediate urban areas & $\begin{array}{l}0.0135^{* * *} \\
(0.00240)\end{array}$ \\
\hline Rural areas & $\begin{array}{l}-0.00491^{*} \\
(0.00261)\end{array}$ \\
\hline Remote areas & $\begin{array}{l}-0.0341 * * * \\
(0.00228)\end{array}$ \\
\hline \multicolumn{2}{|l|}{ Ethnic background (Reference: Danish) } \\
\hline Immigrants from Western countries & $\begin{array}{l}-0.0313 * * * \\
(0.00502)\end{array}$ \\
\hline Immigrants from non-Western countries & $\begin{array}{l}-0.134 * * * \\
(0.00269)\end{array}$ \\
\hline Observations & 317,962 \\
\hline Number of people receiving the type of treatment & 85,375 \\
\hline
\end{tabular}

Note: Standard deviations in parentheses. All predictors at their mean value. Residence region and interactions between income and age are included but not reported here. *** $\mathrm{p}<0.01, * * \mathrm{p}<0.05, * \mathrm{p}<0$. Source: Based on data from Statistics Denmark, the National Danish Diabetes Registry 2012, and information on urbanization from the Ministry of Housing, Urban and Rural Affairs (2013). 
The results indicate a social inequality when it comes to having your feet checked annually. There is significant income inequality in having your feet inspected. The individuals in the second, third and fourth income quartiles have a $2.74 \%, 2.99 \%$ and $1.10 \%$ higher probability, respectively, of visiting a chiropodists compared with those in the first income quartile. Interestingly, the people in the fourth quartile have a significantly lower probability of having visited a chiropodist relative to the people in the second and third quartiles $(p$-value $<0.001)$.

In line with the finding of Ettner et al. (2009), we find that immigrants from Western countries and, even more so, immigrants from non-Western countries have a lower probability of having had their feet inspected by a chiropodist compared to native Danes. More specifically, the western and non-Western immigrants have a $3.13 \%$ and $13.40 \%$ lower probability, respectively. The $13.40 \%$ lower probability is very large considering that the average probability in the sample is approximately $25 \%$.

Another-key variable of interest is the urban index. Here the results suggest that the people living in remote areas have a $3.41 \%$ lower probability of having had a diabetic foot inspection by a chiropodist in 2012, while people living in rural areas have a $0.49 \%$ lower probability of this. Interestingly, the persons living in the intermediate urban areas have a $1.35 \%$ higher probability, compared to the reference group of people living in urban areas.

Men and singles are $0.6 \%$ and $2.1 \%$ less likely, respectively, to visit a chiropodist than women and cohabiting/married people. For each year of age, a person with diabetes have a $0.44 \%$ higher probability of having the feet inspected by a chiropodist. Moreover, the longer people have had the diagnosis the more likely they are to have had their feet inspected by a chiropodist. If the diagnosis was made more than 10 years ago, people with diabetes are $14.5 \%$ more likely to receive preventive treatment, than a person who was diagnosed less than 5 years ago.

\subsection{Heterogeneity analysis}

In Table 2, the average relations are estimated. In the following sections, we will analyse whether the average relations are consistent or if they vary with regard the regional area, the year of diagnosis and the applied urban index. The relations between visiting a chiropodist and the different individual variables on a regional level is of particularly interest, as the Danish health care is administered on regional level. Accordingly, variation across regions will give valuable insight into, which groups of people with diabetes that do or do not visit a chiropodist in each region. Visits to a chiropodist conditional on years since diagnosis may also give important information about potential difference in the relations between visiting a chiropodist and different variables, as the impacts of diabetes increase with years of diagnosis. The analysis will give indications of which groups of people with diabetes that early after diagnose visits a chiropodist. Finally, exploiting the applied urban index may give information about specific groups of people with diabetes who do or do not visit a chiropodist. This might be particularly of interest in the rural and remote areas relative to the urban areas. The descriptive statistics for each sub sample in the heterogeneity analysis are in Appendices Table 1-3.

\section{Regional level}

The regional conditional models are presented in Table 3. 
Table 3: Regional conditional models, 2012, marginal effects

\begin{tabular}{|c|c|c|c|c|c|}
\hline & $\begin{array}{l}\text { Capital } \\
\text { Region of } \\
\text { Denmark }\end{array}$ & $\begin{array}{l}\text { North } \\
\text { Denmark } \\
\text { Region }\end{array}$ & $\begin{array}{l}\text { Central } \\
\text { Denmark } \\
\text { Region } \\
\end{array}$ & $\begin{array}{l}\text { Region of } \\
\text { Southern } \\
\text { Denmark }\end{array}$ & $\begin{array}{l}\text { Region } \\
\text { Zealand }\end{array}$ \\
\hline \multicolumn{6}{|c|}{ Years since diagnosis in registry (Reference: 0-4 years) } \\
\hline \multirow[t]{2}{*}{ 5-10 years } & -0.00438 & $0.0424 * * *$ & $0.0484 * * *$ & $0.0456 * * *$ & $0.0143 * * *$ \\
\hline & $(0.00367)$ & $(0.00576)$ & $(0.00357)$ & $(0.00353)$ & $(0.00512)$ \\
\hline \multirow[t]{2}{*}{ More than 10 years } & $0.0895 * * *$ & $0.174 * * *$ & $0.177^{* * *}$ & $0.177^{* * *}$ & $0.119 * * *$ \\
\hline & $(0.00386)$ & $(0.00612)$ & $(0.00411)$ & $(0.00399)$ & $(0.00529)$ \\
\hline \multirow[t]{2}{*}{ Women (Reference: men) } & $0.00628 * * *$ & $0.0126 * * *$ & 0.00163 & 0.00367 & -0.00394 \\
\hline & $(0.00163)$ & $(0.00320)$ & $(0.00520)$ & $(0.00334)$ & $(0.00329)$ \\
\hline \multicolumn{6}{|c|}{ Income quartiles (Reference: $\mathbf{1}^{\text {st }}$ quartile) } \\
\hline \multirow[t]{2}{*}{$2^{\text {nd }}$ income quartile } & $0.0301 * * *$ & $0.0312 * * *$ & $0.0191 * * *$ & $0.0246 * * *$ & $0.0170 * *$ \\
\hline & $(0.00511)$ & $(0.00815)$ & $(0.00527)$ & $(0.00492)$ & $(0.00691)$ \\
\hline \multirow[t]{2}{*}{$3^{\text {rd }}$ income quartile } & $0.0426 * * *$ & 0.0102 & $0.0209 * * *$ & $0.0275 * * *$ & $0.0273 * * *$ \\
\hline & $(0.00480)$ & $(0.00767)$ & $(0.00497)$ & $(0.00473)$ & $(0.00647)$ \\
\hline \multirow[t]{2}{*}{$4^{\text {th }}$ income quartile } & $0.0186 * * *$ & 0.00136 & -0.00496 & $0.0171 * * *$ & $0.0163^{* *}$ \\
\hline & $(0.00478)$ & $(0.00873)$ & $(0.00538)$ & $(0.00538)$ & $(0.00704)$ \\
\hline \multirow[t]{2}{*}{ Age } & $0.00459 * * *$ & $0.00521 * * *$ & $0.00389 * * *$ & $0.00319 * * *$ & $0.00513 * * *$ \\
\hline & $(0.000123)$ & $(0.000202)$ & $(0.000128)$ & $(0.000125)$ & $(0.000179)$ \\
\hline \multicolumn{6}{|c|}{ Education (Reference: basic school) } \\
\hline \multirow[t]{2}{*}{ Vocational education } & $0.0137 * * *$ & -0.00408 & 0.000264 & 0.000199 & $0.0136 * * *$ \\
\hline & $(0.00369)$ & $(0.00597)$ & $(0.00379)$ & $(0.00371)$ & (0.00498) \\
\hline Short-cycle higher & 0.00740 & -0.0201 & -0.0118 & 0.00394 & 0.00339 \\
\hline education & $(0.00917)$ & $(0.0172)$ & $(0.0101)$ & $(0.00990)$ & $(0.0135)$ \\
\hline Medium-cycle higher & -0.00809 & $-0.0167^{*}$ & $-0.0169 * * *$ & $-0.0132 * *$ & $-0.0197^{* *}$ \\
\hline education & $(0.00550)$ & $(0.00985)$ & $(0.00605)$ & $(0.00603)$ & $(0.00820)$ \\
\hline Long-cycle higher & $-0.0493 * * *$ & $-0.0736 * * *$ & $-0.0701 * * *$ & $-0.0504 * * *$ & $-0.0582 * * *$ \\
\hline education & $(0.00684)$ & $(0.0171)$ & $(0.00924)$ & $(0.0108)$ & $(0.0142)$ \\
\hline \multirow[t]{2}{*}{ Unknown } & $-0.0738 * * *$ & $-0.0644 * * *$ & $-0.0602 * * *$ & $-0.0743 * * *$ & $-0.0857 * * *$ \\
\hline & $(0.00716)$ & $(0.0128)$ & $(0.00840)$ & $(0.00768)$ & $(0.0114)$ \\
\hline \multicolumn{6}{|c|}{ Marital status (Reference: living alone) } \\
\hline \multirow[t]{2}{*}{ Other } & $-0.00941 *$ & -0.0163 & -0.00974 & -0.00663 & 0.0121 \\
\hline & $(0.00557)$ & $(0.0114)$ & $(0.00697)$ & $(0.00691)$ & $(0.00845)$ \\
\hline \multirow[t]{2}{*}{ Married/cohabiting } & $0.0328 * * *$ & 0.00241 & 0.00360 & $0.0213 * * *$ & $0.0381 * * *$ \\
\hline & $(0.00368)$ & $(0.00623)$ & $(0.00393)$ & $(0.00388)$ & $(0.00525)$ \\
\hline \multicolumn{6}{|c|}{ Urban index, based on parishes (Reference: Urban areas) } \\
\hline \multirow[t]{2}{*}{ Intermediate urban areas } & $0.0499 * * *$ & $0.0413 * * *$ & $0.0169 * * *$ & $-0.0383 * * *$ & $0.0310 * * *$ \\
\hline & $(0.00797)$ & $(0.00707)$ & $(0.00465)$ & $(0.00434)$ & $(0.00582)$ \\
\hline \multirow[t]{2}{*}{ Rural areas } & $0.0220 * * *$ & $-0.0627 * * *$ & 0.000226 & $-0.00987 * *$ & $0.0397 * * *$ \\
\hline & $(0.00849)$ & $(0.00721)$ & $(0.00448)$ & $(0.00450)$ & $(0.00929)$ \\
\hline \multirow[t]{2}{*}{ Remote areas } & -0.00308 & $-0.0256 * * *$ & $-0.0152 * * *$ & $-0.0629 * * *$ & $-0.0477 * * *$ \\
\hline & $(0.00802)$ & $(0.00651)$ & $(0.00466)$ & $(0.00435)$ & $(0.00556)$ \\
\hline \multicolumn{6}{|c|}{ Ethnic background (Reference: Danish) } \\
\hline Immigrants from Western & $-0.0359 * * *$ & -0.0180 & $-0.0255^{* *}$ & $-0.0226 * *$ & -0.0201 \\
\hline countries & $(0.00833)$ & $(0.0199)$ & $(0.0122)$ & $(0.00997)$ & $(0.0155)$ \\
\hline Immigrants from non- & $-0.135 * * *$ & $-0.115^{* * *}$ & $-0.115^{* * *}$ & $-0.135 * * *$ & $-0.156 * * *$ \\
\hline Western countries & $(0.00439)$ & $(0.0139)$ & $(0.00611)$ & $(0.00589)$ & $(0.00923)$ \\
\hline Observations & 84,598 & 34,433 & 73,260 & 76,653 & 49,018 \\
\hline $\begin{array}{l}\text { Number of people visiting a } \\
\text { chiropodist }\end{array}$ & 23,086 & 10,253 & 18,560 & 19,303 & 15,869 \\
\hline
\end{tabular}

Note: Standard deviations in parentheses. All predictors at their mean value. Residence region and interactions between income and age are included but not reported here. $* * * \mathrm{p}<0.01, * * \mathrm{p}<0.05, * \mathrm{p}<0$. 
In the relation between years of diagnosis and having seen a chiropodist, there seems to be a general trend across the regions. The more years since the diagnosis the higher propensity that a person with diabetes has seen a chiropodist. The estimates for having had the diagnose for 5-10 years in the case of Capital Region of Denmark and Region of Southern Denmark are though small, and insignificant in the case of the former. The differences between men and women are only significant in North Denmark Region and Capital Region of Denmark - both in favour of women. Moving on to the income relations, we generally find higher probabilities of visiting a chiropodist in the $2^{\text {nd }}-4^{\text {th }}$ income quartile. Some of the estimates are though insignificant, such the estimates for the $3^{\text {rd }}$ and $4^{\text {th }}$ quartile in the North Denmark Region sample. All age relations estimates are positive as in the model in Table 2. The estimates for the educational relations are generally consistent. People with a medium-cycle or long-cycle higher education have a lower probability of having seen a chiropodist in all the regional samples. The influence of being married/cohabiting is generally consistent, though not always significant, when compared to the estimated relations in Table 2. The rural index relations are mixed across the regions. In the case of Region of Southern Denmark, people living in intermediate urban areas have a significant lower probability of visiting a chiropodist, compared to person living in urban areas. Accordingly, the Region of Southern Denmark people with diabetes in the urban areas have the highest likelihood for having seen a chiropodist.

Furthermore, people in rural areas in Capital Region of Denmark and Region Zealand have a higher probability of visiting a chiropodist, compared to person living in urban areas in the two regions. The immigrant relations are consistent across the five regions compared to Table 2, though the estimates for Western Immigrants are not significant in all models.

\section{Years since diagnosis}

In Table 4, the estimated relations between gender in Table 2 vary significantly conditional on year of diagnosis. Women appear to be better in visiting a chiropodist in the first years after been diagnosed with diabetes, when compared to men. However, when comparing men and women among those who have had their diagnosis in more than ten years, we see the opposite and significant relation. The marital status, education and income relations are in line with the findings in Table 2. An exception is that people in the $4^{\text {th }}$ income quartile does not have a significantly higher propensity compared to people in the $1^{\text {st }}$ income quartile group conditional on more than ten years since diagnosis.

With regards to the urban index, we find that only people living in remote areas have a lower probability of having visited a chiropodist, conditional on 0-4 years since diagnose. As the years since diagnose increase, the models suggest an increase in rural and remote area inequality. This suggests that among the people with diabetes that potentially need an annual feet status the most (10+ years since diagnose) people particularly in remote and rural areas are worse off. The same relations seem to be present in the case of being an immigrant from a Western and particularly non-Western country. The longer since diagnosis, the less likely a visit to a chiropodist is, when compared to people with diabetes with a Danish origin. 
Table 4: $\quad$ Year of diagnosis conditional models, 2012, marginal effects

\begin{tabular}{|c|c|c|c|c|}
\hline & & $\begin{array}{l}\text { Diagnose } \\
0-4 \text { years }\end{array}$ & $\begin{array}{l}\text { Diagnose } \\
5-10 \text { years }\end{array}$ & $\begin{array}{l}\text { Diagnose } \\
>\text { 10years }\end{array}$ \\
\hline \multirow{2}{*}{\multicolumn{2}{|c|}{ Women (Reference: men) }} & $0.0246 * * *$ & -0.000501 & $-0.0115 * * *$ \\
\hline & & $(0.00261)$ & $(0.00272)$ & $(0.00317)$ \\
\hline \multicolumn{5}{|c|}{ Income quartiles (Reference: $1^{\text {st }}$ quartile) } \\
\hline \multirow{2}{*}{\multicolumn{2}{|c|}{$2^{\text {nd }}$ income quartile }} & $0.0222 * * *$ & $0.0268 * * *$ & $0.0255^{* * *}$ \\
\hline & & $(0.00411)$ & $(0.00415)$ & $(0.00487)$ \\
\hline \multirow{2}{*}{\multicolumn{2}{|c|}{$3^{\text {rd }}$ income quartile }} & $0.0341 * * *$ & $0.0290 * * *$ & $0.0220 * * *$ \\
\hline & & $(0.00377)$ & $(0.00394)$ & $(0.00470)$ \\
\hline \multirow{2}{*}{\multicolumn{2}{|c|}{$4^{\text {th }}$ income quartile }} & $0.0244 * * *$ & $0.0147^{* * *}$ & -0.00778 \\
\hline & & $(0.00395)$ & $(0.00427)$ & $(0.00518)$ \\
\hline \multirow{2}{*}{\multicolumn{2}{|c|}{ Age }} & $0.00281 * * *$ & $0.00349 * * *$ & $0.00624 * * *$ \\
\hline & & (9.97e-05) & $(0.000106)$ & $(0.000123)$ \\
\hline \multicolumn{5}{|c|}{ Education (Reference: basic school) } \\
\hline \multirow{2}{*}{\multicolumn{2}{|c|}{ Vocational education }} & $0.00818 * * *$ & $0.00785^{* *}$ & $-5.22 e-05$ \\
\hline & & $(0.00295)$ & $(0.00308)$ & $(0.00361)$ \\
\hline & Short-cycle higher & 0.00744 & -0.0114 & 0.00368 \\
\hline & education & $(0.00774)$ & $(0.00812)$ & $(0.00962)$ \\
\hline & Medium-cycle higher & -0.00411 & $-0.0166 * * *$ & $-0.0201 * * *$ \\
\hline & education & $(0.00462)$ & $(0.00489)$ & $(0.00578)$ \\
\hline & Long-cycle higher & $-0.0336 * * *$ & $-0.0744 * * *$ & $-0.0627 * * *$ \\
\hline & education & $(0.00700)$ & $(0.00703)$ & $(0.00890)$ \\
\hline & \multirow[t]{2}{*}{ Unknown } & $-0.0510 * * *$ & $-0.0705 * * *$ & $-0.0984 * * *$ \\
\hline & & $(0.00648)$ & $(0.00657)$ & $(0.00752)$ \\
\hline \multicolumn{5}{|c|}{ Marital status (Reference: living alone) } \\
\hline \multirow{2}{*}{\multicolumn{2}{|c|}{ Other }} & 0.00461 & $-0.0125 * *$ & $-0.0124 * *$ \\
\hline & & $(0.00504)$ & $(0.00535)$ & $(0.00624)$ \\
\hline \multirow{2}{*}{\multicolumn{2}{|c|}{ Married/cohabiting }} & $0.0183^{* * *}$ & $0.0161 * * *$ & $0.0293 * * *$ \\
\hline & & $(0.00298)$ & $(0.00318)$ & $(0.00376)$ \\
\hline \multicolumn{5}{|c|}{ Urban index, based on parishes (Reference: Urban areas) } \\
\hline \multirow{2}{*}{\multicolumn{2}{|c|}{ Intermediate urban areas }} & 0.00238 & $0.0111^{* * *}$ & $0.0248 * * *$ \\
\hline & & $(0.00384)$ & $(0.00391)$ & $(0.00470)$ \\
\hline \multirow{2}{*}{\multicolumn{2}{|c|}{ Rural areas }} & -0.00137 & -0.00237 & $-0.0117^{* *}$ \\
\hline & & $(0.00418)$ & $(0.00438)$ & $(0.00507)$ \\
\hline \multirow{2}{*}{\multicolumn{2}{|c|}{ Remote areas }} & $-0.0397 * * *$ & $-0.0308 * * *$ & $-0.0384 * * *$ \\
\hline & & $(0.00358)$ & $(0.00380)$ & $(0.00455)$ \\
\hline \multicolumn{5}{|c|}{ Ethnic background (Reference: Danish) } \\
\hline & Immigrants from Western & $-0.0192 * *$ & $-0.0301 * * *$ & $-0.0423 * * *$ \\
\hline & countries & $(0.00787)$ & $(0.00823)$ & $(0.0102)$ \\
\hline & Immigrants from non- & $-0.112 * * *$ & $-0.128 * * *$ & $-0.167 * * *$ \\
\hline & Western countries & $(0.00408)$ & $(0.00454)$ & $(0.00573)$ \\
\hline \multicolumn{2}{|l|}{ Observations } & 103,858 & 109,100 & 105,004 \\
\hline \multicolumn{2}{|c|}{ Number of people visiting a chiropodist } & 21,877 & 26,981 & 38,213 \\
\hline
\end{tabular}

Note: Standard deviations in parentheses. All predictors at their mean value. Residence region and interactions between income and age are included but not reported here. *** $\mathrm{p}<0.01, * * \mathrm{p}<0.05, * \mathrm{p}<0$. Source: Based on data from Statistics Denmark, the National Danish Diabetes Registry 2012, and information on urbanization from the Ministry of Housing, Urban and Rural Affairs (2013). 


\section{Urban index}

The final analysis of heterogeneous relations is done with regard to the urban index. The models are in Table 5.

Except from minor differences in the significance of the parameter estimates, the relations between visiting a chiropodist and the tested variables seem to stable across the four urban area types and overall in line with the average estimated relations in in Table 2. The models only find significant differences in gender in the urban and remote areas. In both cases, females have a higher propensity (though $<1 \%$ ) to have visited a chiropodist compared to males with diabetes. The income patterns also seem to be in line with the results in Table 2 and across urban area types, though the estimate for the fourth income quartile is insignificant in rural and remote areas. Finally, it is worth noticing that the Western immigrants in the remote areas do not have a significant lower propensity to have visited a chiropodist, when compared to a native Danish person with diabetes.

\section{Discussion}

To our knowledge, this is the first study on publicly subsidised foot therapy among people with diabetes performed on a complete nationally representative sample. We find that $73 \%$ people with diabetes do not have their feet inspected by a chiropodist. Our model results indicate that some socio-demographic groups have a lower likelihood of having received a foot inspection. Specifically, we found that, ethnic minorities, people living in rural and remote areas, singles, men and the lowest income groups are significantly less likely to visit a chiropodist.

Starting with the latter, it can be argued whether there are any economic barriers to visit a chiropodist, when the costs are as low as $25 €$. Our results suggest that it may be the case anyway. The persons with diabetes belonging to the lowest income group has an annual gross income of less than EUR 15,300€. Prioritising $25 €$ might be a major obstacle for these persons with diabetes. However, in the highest $25 \%$ of the income distribution we find an unexpected less positive trend in relation to visiting chiropodists. An explanation might be that this study is limited to examining the publicly subsidised podiatry services. The results of the analysis should therefore be seen in the light of the fact that some people may be more likely to receive treatment from non-subsidy eligible chiropodists, in that people with high income might use private chiropodists instead. Almost $45 \%$ of all registered chiropodists do not receive any subsidies (sundhed.dk, 2015). One of the reasons for choosing an unsubsidised chiropodist is a potential higher flexibility in terms of getting an acute appointment. The waiting time for an appointment at a subsidised chiropodist is as high as 6 months (or even higher in some areas), according to the Danish regional health assessments (Region Zealand, 2015; The North Denmark Region, 2016; The Capital Region of Denmark, 2013). This might make an unsubsidised and more expensive chiropodist a preferable choice, if the disutility associated with longer waiting time exceeds the higher direct costs of treatment. Clearly, this is speculative, but it is in line with the positive relationship between higher income level and a higher demand for private health care compared to public health care, as found based on UK data (Propper, 2000). The results are also in line with other findings of a positive relationship between longer waiting lists for public health care and demand for private health insurances (Besley, 1999). However, further research is needed to investigate this possible explanation. 
Table 5: Urban index conditional models, 2012, marginal effects

\begin{tabular}{|c|c|c|c|c|}
\hline & Urban & $\begin{array}{l}\text { Intermediate } \\
\text { urban }\end{array}$ & Rural & Remote \\
\hline \multicolumn{5}{|l|}{ Years since diagnosis in registry } \\
\hline \multicolumn{5}{|l|}{ (Reference: $0-4$ years) } \\
\hline \multirow[t]{2}{*}{$5-10$ years } & $0.0212 * * *$ & $0.0404 * * *$ & $0.0341^{* * *}$ & $0.0401 * * *$ \\
\hline & $(0.00245)$ & $(0.00471)$ & $(0.00526)$ & $(0.00441)$ \\
\hline \multirow[t]{2}{*}{ More than 10 years } & $0.132 * * *$ & $0.174 * * *$ & $0.150 * * *$ & $0.154 * * *$ \\
\hline & $(0.00265)$ & $(0.00515)$ & $(0.00573)$ & $(0.00483)$ \\
\hline \multirow[t]{2}{*}{ Women (Reference: men) } & $0.00572 * * *$ & -0.00603 & 0.00560 & $0.00737^{*}$ \\
\hline & $(0.00221)$ & $(0.00431)$ & $(0.00477)$ & $(0.00400)$ \\
\hline \multicolumn{5}{|l|}{ Income quartiles (Reference: $1^{\text {st }}$ quartile) } \\
\hline \multirow[t]{2}{*}{$2^{\text {nd }}$ income quartile } & $0.0282 * * *$ & $0.0239 * * *$ & $0.0260 * * *$ & $0.0135^{* *}$ \\
\hline & $(0.00345)$ & $(0.00642)$ & $(0.00783)$ & $(0.00620)$ \\
\hline \multirow[t]{2}{*}{$3^{\text {rd }}$ income quartile } & $0.0331 * * *$ & $0.0253^{* * *}$ & $0.0224 * * *$ & $0.0211^{* * *}$ \\
\hline & $(0.00327)$ & $(0.00620)$ & $(0.00711)$ & $(0.00583)$ \\
\hline \multirow[t]{2}{*}{$4^{\text {th }}$ income quartile } & $0.0131 * * *$ & $0.0138 *$ & 0.00659 & 0.00354 \\
\hline & $(0.00341)$ & $(0.00715)$ & $(0.00762)$ & $(0.00660)$ \\
\hline \multirow[t]{2}{*}{ Age } & $0.00418 * * *$ & $0.00415^{* * *}$ & $0.00470 * * *$ & $0.00430 * * *$ \\
\hline & $(8.33 e-05)$ & $(0.000164)$ & $(0.000196)$ & $(0.000165)$ \\
\hline \multicolumn{5}{|l|}{ Education (Reference: basic school) } \\
\hline \multirow[t]{2}{*}{ Vocational education } & $0.00820 * * *$ & $-0.00847 *$ & $0.0142 * * *$ & 0.00209 \\
\hline & $(0.00252)$ & $(0.00481)$ & $(0.00543)$ & $(0.00456)$ \\
\hline \multirow[t]{2}{*}{ Short-cycle higher education } & -0.00304 & 0.000705 & -0.00189 & 0.00786 \\
\hline & $(0.00643)$ & $(0.0136)$ & $(0.0140)$ & $(0.0132)$ \\
\hline \multirow[t]{2}{*}{ Medium-cycle higher education } & $-0.0117 * * *$ & $-0.0308 * * *$ & -0.00330 & $-0.0170 * *$ \\
\hline & $(0.00387)$ & $(0.00787)$ & $(0.00893)$ & $(0.00763)$ \\
\hline \multirow[t]{2}{*}{ Long-cycle higher education } & $-0.0534 * * *$ & $-0.0646 * * *$ & $-0.0871 * * *$ & $-0.0595 * * *$ \\
\hline & (0.00529) & $(0.0142)$ & $(0.0144)$ & $(0.0143)$ \\
\hline \multirow[t]{2}{*}{ Unknown } & $-0.0715^{* * *}$ & $-0.0680 * * *$ & $-0.0815^{* * *}$ & $-0.0682 * * *$ \\
\hline & (0.00509) & $(0.0106)$ & $(0.0124)$ & $(0.0101)$ \\
\hline \multicolumn{5}{|l|}{ Marital status (Reference: living alone) } \\
\hline \multirow[t]{2}{*}{ Other } & $-0.0129 * * *$ & -0.00243 & -0.00710 & 0.0104 \\
\hline & $(0.00425)$ & $(0.00950)$ & $(0.00900)$ & $(0.00768)$ \\
\hline \multirow[t]{2}{*}{ Married/cohabiting } & $0.0231 * * *$ & $0.0123^{* *}$ & $0.0133 * *$ & $0.0285^{* * *}$ \\
\hline & $(0.00255)$ & $(0.00497)$ & (0.00599) & $(0.00487)$ \\
\hline \multicolumn{5}{|l|}{ Ethnic background (Reference: Danish) } \\
\hline \multirow[t]{2}{*}{ Immigrants from Western countries } & $-0.0283 * * *$ & $-0.0252 *$ & $-0.0393 * *$ & -0.0199 \\
\hline & $(0.00658)$ & $(0.0136)$ & $(0.0172)$ & $(0.0132)$ \\
\hline \multirow[t]{2}{*}{ Immigrants from non-Western countries } & $-0.137 * * *$ & $-0.134 * * *$ & $-0.0983 * * *$ & $-0.0736 * * *$ \\
\hline & $(0.00318)$ & $(0.00878)$ & $(0.0174)$ & $(0.0181)$ \\
\hline Observations & 175,831 & 51,933 & 38,327 & 51,871 \\
\hline Number of people visiting a chiropodist & 47,316 & 15,866 & 10,368 & 13,488 \\
\hline
\end{tabular}

Note: Standard deviations in parentheses. All predictors at their mean value. Residence region and interactions between income and age are included but not reported here. *** $\mathrm{p}<0.01, * * \mathrm{p}<0.05, * \mathrm{p}<0$. Source: Based on data from Statistics Denmark, the National Danish Diabetes Registry 2012, and information on urbanization from the Ministry of Housing, Urban and Rural Affairs (2013). 
Moving on the findings that immigrants from Western and particular non-Western countries have a lower probability of visiting a chiropodist, at least two factors may explain the findings. First, Ettner et al. (2009) find a higher self-production of foot care among ethnic groups relative to general population. With this in mind, we would expect (all else being equal) and we find a lower demand for professional foot care among the ethnic groups of persons with diabetes. Naturally, we cannot make such direct comparisons between the demands for foot care in the US and Denmark, but the two studies seem to support each other. The second factor that can influence probability of visiting a chiropodist may be explained by simple language barriers/ cultural differences. Among nonelderly with a health insurance Fiscella et al. (2002) find that disparities in health-care use by race and Hispanic ethnicity (Fiscella et al., 2002). Fiscella et al. (2002) argue that the disparities in care can largely explained by differences in English fluency. Similar results and languages barrier arguments are highlighted in an intervention study aimed at increasing the likelihood on receiving at least one hemoglobin A1c (HbA1c) test, LDL cholesterol test and retinal examination each year among people with diabetes (Meng et al., 2016).

Interestingly, we find a lower demand for having the feet examined by a chiropodist among the more highly educated persons with diabetes relative to the persons with the lowest educational level. It is difficult to verify the causal process that might be behind these results. Ettner et al. (2009) found that more highly educated persons have a lower selfproduction of health care, which would make us expect a higher demand for professional care in our study. This is in contrast to our findings. However, one explanation might be, as in the case of the higher income groups that the demand for private health care relative to public care increases with the level of education, as found by Propper (2000).

Finally, we would like to touch upon the estimated urban density relations. The results denote a negative spatial relation between the level of urbanisation and the probability of having visited a chiropodist the past year. In the figure below, we have plotted the distribution of chiropodists in Central Denmark Region and the division of the urban/rural areas used on our analysis.

\section{Figure 1: Distribution of chiropodist in Central Denmark Region with regard to applied urban index}

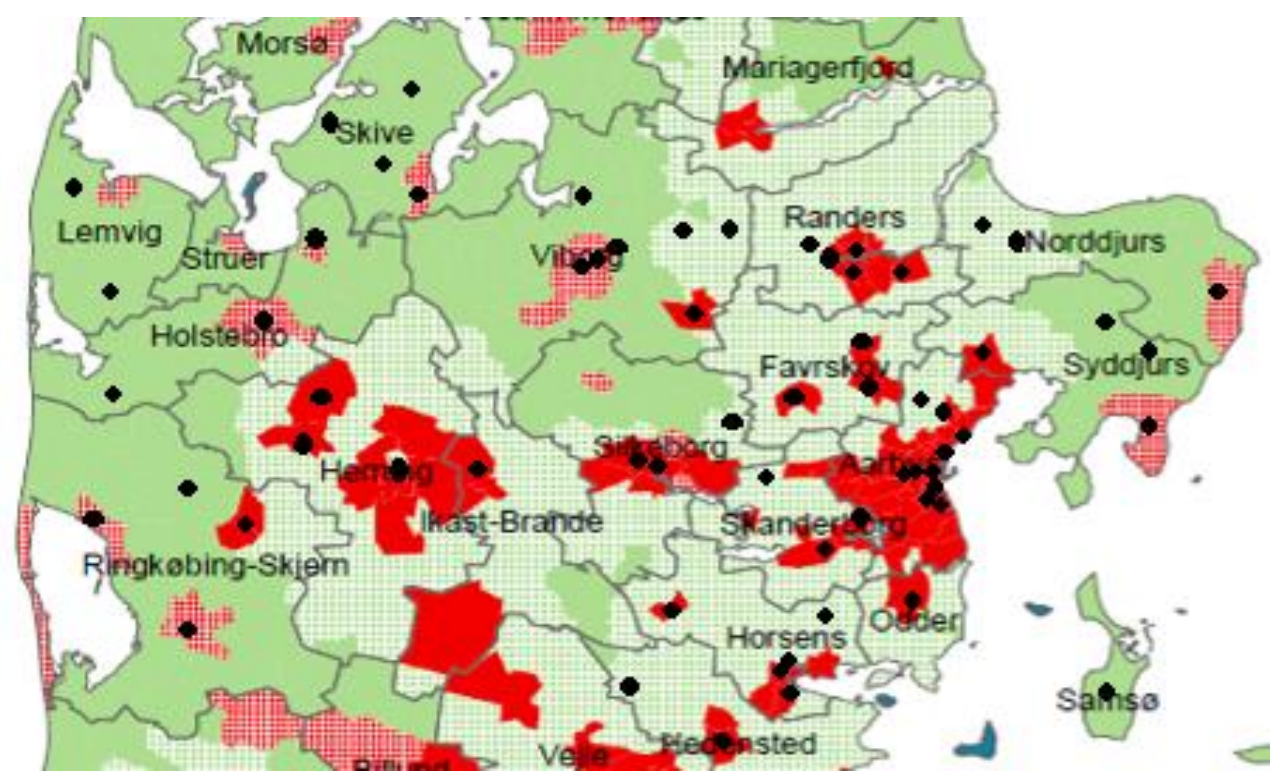

Note: The figure is based on our own regional map and the map in Central Denmark Region (2011) page 14 (Central Denmark Region, 2011). 
Figure 1 illustrates that people with diabetes living in remote (green) areas have substantially longer distance to the nearest chiropodist, compared to persons with diabetes living in urban (red) or intermediate (red and white chequered) urban areas (Central Denmark Region, 2011). Our models clearly suggest that distance to the nearest chiropodist seems to drive the urban/rural relations. These results are in line with the health demand and spatial literature, see for example Luo and Wang (2003) and Wang and Luo (2005). However, it does not explain why we observe that persons with diabetes in the urban areas have a lower probability to have visited a chiropodist compared to persons with diabetes in intermediate urban areas. One potential explanation could be that the number subsidised chiropodist in the urban areas are relatively few compared to the number of persons with diabetes. Another explanation may be that there is a higher number of non-subsidised chiropodist in the urban areas, which may make especially high-income groups to use the non-subsidised chiropodists. Unfortunately, there exist no such measure of the number of persons with diabetes per chiropodist on our urban index level. This makes it difficult to verify this argument. In summary, the spatial findings suggest that an increase in probability of visiting a chiropodist may be obtained by reducing the spatial barriers. The spatial barriers could be reduced by more physical chiropodists in the remote areas or by using mobile chiropodists.

A final set of results worth discussing are the heterogeneity models. There are some differences in the models across health regions, years since diagnosis and urban index area. However, the conditional models do not give strong indications of that the observed inequalities in Table 2 differ markedly. One result that should be pointed out is the apparent increasing in inequality between people different ethnical backgrounds in relation to the years since diagnosis. The results point towards that the gap between people with Danish and non-Western origin increases the longer people have had a diagnose. People from a nonWestern country who have had diabetes for more than ten years have as much as $16.7 \%$ lower probability of having visited at chiropodist, when compared to native Danes. This numbers should be seen in light that the average probabilities of visiting a chiropodist are $26.6 \%, 32.8$ and $57.1 \%$ for people who had diabetes for less than five, five to ten and more than ten years, respectively (see Appendices Table 2).

\subsection{Data and method}

The validity of the data used is crucial. The Health Insurance Service Registry is generally considered credible, as it is considered unlikely that there are systematic errors in relation to the registered consumption among people with different socioeconomic characteristics. This is mainly due to registrations being necessary for the chiropodists to receive remuneration for their service.

The Diabetes Registry is a validated registry identifying the majority of people with diabetes (Carstensen et al., 2008; Carstensen et al., 2011; Green et al., 2015). However, some inclusion criteria are more uncertain than others. In sensitivity analyses, the logistic regression was divided in relation to the inclusion criteria and the inclusion dates. Furthermore, a regression was done exclusively on the people who met only the two most uncertain inclusion criteria for blood glucose measurements. Most of the results were robust. The greatest uncertainty was found in the estimates of gender and regions. In general, the results do not change when we perform different sensitivity analyses.

One drawback of our study is that we only have data for 2012, which is the most recent data presently available. We are not familiar with organizational changes of chiropodists potentially affecting the interpretation of the results in the current environment (primo 2017). This means that the analyses only look at a snapshot of the conditions in 2012, 
without including historical factors, such as previous diagnoses or foot treatments. This means that if a person used a professional caregiver in 2011, and thus did not require treatment in 2012, this could lead to biased results. The credibility of the results could be strengthened by expanding the analyses to include information on, for example, previous foot ulcers and disease history (e.g. Charlson Co-morbidity Index). Furthermore, in our study it is not possible to show causal effects of foot therapy. This would necessitate further studies of the relationship between foot therapy and amputations and other treatments in hospital.

\section{Conclusions}

According to the international guidelines on the prevention of foot problems in diabetes, all patients with diabetes should, as a rule, have an annual visit to an authorised foot clinician. Therefore, the $27 \%$ of the identified people with diabetes who have visited a foot therapist constitute a low proportion, considering the clinical recommendations. Thus, it would be interesting to investigate whether there are socioeconomic differences that can give a picture of whether there are inequalities as to who seek publicly supported foot therapy in Denmark.

The results indicate that the use of foot-care services for persons with diabetes is unevenly distributed. Among the people identified with diabetes, those with a low income, ethnic minorities (especially non-Western), living in rural and remote areas, men and singles have a lower likelihood of having receiving foot therapy than those with a high income, a Danish background, living in urban areas, women and cohabitants/married people.

The results indicate that there is a potential for motivating more people to visit a chiropodist for diabetic foot treatment. Understanding these differences opens up the possibility of reducing health inequalities in relation to preventive foot therapy and thereby possibly preventing costly treatments in the health system.

\section{References}

Armstrong, D., Laver,y L. and Harkless L. (1998) Validation of a Diabetic Wound Classification System: The Contribution of Depth, Infection, and Ischemia to Risk of Amputation. Diabetes Care, 21(5), 855-9.

Becker, G.S. (1965) A Theory of the Allocation of Time. The Economic Journal, 75(299), 493-517.

Besley, T., Hall, J. and Preston, I. (1999) The Demand for Private Health Insurance: Do Waiting Lists Matter? Journal of Public Economics, 72(2), 155-181.

Boulton, A.J., Vileikyte, L., Ragnarson-Tennvall, G. and Apelqvist, J. (2005) The Global Burden of Diabetic Foot Disease. The Lancet, 366(9498), 1719-1724.

Carstensen, B., Kristensen, J., Ottosen, P. and Borch-Johnsen, K. (2008) The Danish National Diabetes Register: Trends in Incidence, Prevalence and Mortality. Diabetologia, 51(12), 21872196.

Carstensen, B., Kristensen, J., Marcussen, M. and Borch-Johnsen, K. (2011) The National Diabetes Register. Scandinavian Journal of Public Health, 39(7), 58-61.

Cavanagh, P.R., Lipsky, B.A., Bradbury, A.W. and Botek, G. (2005) Treatment for Diabetic Foot Ulcers. The Lancet, 366(9498), 1725-1735.

Central Denmark Region. (2011) Practice Plan for Chiropodist in Region Midtjylland 2012-2014 [in Danish: Praksisplan for Fodterapeuter i Region Midtjylland 2012-2014] Viborg: Regionshuset

Cowell, A.J. (2006) The Relationship Between Education and Health Behavior: Some Empirical Evidence. Health Economics, 15(2), 125-146. 
Cutler, D.M., Glaeser, E.L and Shapiro, J.M. (2003) Why Have Americans Become More Obese? Journal of Economic Perspectives, 17(3), 93-118.

Edmonds, M.E. (1999). Progress in Care of the Diabetic Foot. The Lancet, 354(9175), 270-272.

Ettner, S.L., Cadwell, B.L., Russell, L.B., Brown, A., Karter, A.J., Safford, M., Mangione, C.M., Beckles, G.L.A., Herman, W.H. and Thompson, T.J. (2009) Investing Time in Health: Do Socioeconomically Disadvantaged Patients Spend More or Less Extra Time on Diabetes Selfcare? Health Economics, 18(6), 645-663.

IDF (2015) Diabetes Atlas Update. 7th ed. Belgium: International Diabetes Federation.

Danish Health Authority (2011) Diabetic Foot Ulcer. A Medical Technology Assessment [In Danish: Diabetiske fodsår. En medicinsk teknologivurdering (MTV). Medicinsk Teknologivurdering;13(2).

Fiscella, K., Franks, P., Doescher, M. and Saver, B. (2002) Disparities in Health Care by Race, Ethnicity, and Language Among the Insured: Findings From a National Sample. Medical Care, 40(1), 52-59.

George, H., Rakesh, P., Krishna, M., Alex, R., Abraham, V., George, K. and Prasad, J.H. (2013) Foot Care Knowledge and Practices and the Prevalence of Peripheral Neuropathy among People with Diabetes Attending a Secondary Care Rural Hospital in Southern India. Journal of Family Medicine and Primary Care, 2(1), 27-32.

Gibson, T.B., Driver, V.R., Wrobel, J.S., Christina, J.R., Bagalman E, Defrancis, R, Garoufalis, M.G., Carls, G.S. and Gatwood, J. (2014) Podiatrist Care and Outcomes for Patients with Diabetes and Foot Ulcer. International Wound Journal, 11(6), 641-648.

Green, A., Sorts $\varnothing$, C., Jensen, P.B. and Emneus, M. (2015) Validation of the Danish National Diabetes Register. Clinical Epidemiology, 7, 5-15

Grossman, M. (1972) On the Concept of Health Capital and the Demand for Health. Journal of Political Economy 1972, 80(2), 223-255.

King, H., Aubert, R. and Herman, W. (1998) Global Burden of Diabetes, 1995- 2025: Prevalence, Numerical Estimates, and Projections. Diabetes Care, 21(9), 1414-31.

Kruse, M. and Nørregaard, J. (2012) Associated Costs of of Municipalities and Regions Omkostninger for kommuner og regioner ved udvalgte senfølger til diabetes. Copenhagen: Dansk Sundhedsinstitut

Lavery, L.A., Wunderlich, R.P. and Tredwell, J.L. (2005) Disease Management for the Diabetic Foot: Effectiveness of a Diabetic Foot Prevention Program to Reduce Amputations and Hospitalizations. Diabetes Research and Clinical Practice, 70(1), 31-37.

Lavery, L.A, Hunt, N.A, LaFontaine, J., Baxter, C.L., Ndip, A. and Boulton, A.J.M. (2010) Diabetic Foot Prevention; A Neglected Opportunity in High-risk Patients. Diabetes Care, 33(7), 14601462.

Luo, W. and Wang, F. (2003) Measures of Spatial Accessibility to Health Care in a GIS Environment: Synthesis and a Case Study in the Chicago Region. Environment and Planning B: Planning and Design, 30(6), 865-884.

Meng, Y., Diamant, A., Jones, J., Lin, W., Chen, X., Wu, S, Pourat, N., Roby, D. and Kominski, G.F. (2016) Racial and Ethnic Disparities in Diabetes Care and Impact of Vendor- Based Disease Management Programs. Diabetes Care, 39(5), 743-749.

Ministry of Housing, Urban and Rural Affairs (2013) Regional- og Landdistriktspolitisk



Mirmiran, R., Page, J.C., Armstrong, J.R. and Killian R. (2000) Barriers to Podiatric Care among Diabetic Patients in the San Francisco Bay Area. The Journal of Foot and Ankle Surgery,39(5):301-304. 
Nather, A., Chionh, S.B., Wong, K.L., Koh Si Qi, O., Chan, Y.H., Xinyi. L. and Nambiar, A. (2010) Socioeconomic Profile of Diabetic Patients with and without Foot Problems. Diabetic Foot \& Ankle, 1(0), 1-6.

Nita, M.E., Eliaschewitz, F.G., Ribeiro, E., Asano, E., Barbosa, E., Takemoto, M., Donato, B., Rached, R. and Rahel, E. (1992) Cost- Effectiveness and Budget Impact of Saxagliptine as Additional Therapy to Metformin for the Treatment of Diabetes Mellitus Type 2 in the Brazilian Private Health System. Revista da Associação Médica Brasileira, 58(3), 294-301.

Plank, J., Haas, W., Rakovac, I., Gorzer, E., Sommer, R., Siebenhofer A. and Pieber, T.R. (2003) Evaluation of the Impact of Chiropodist Care in the Secondary Prevention of Foot Ulcerations in Diabetic Subjects. Diabetes Care, 26(6), 1691-5.

Pollock, R.D., Unwin, N.C. and Connolly, V. (2004) Knowledge and Practice of Foot Care in People with Diabetes. Diabetes Research and Clinical Practice, 64(2), 117-122.

Priebe, S., Sandhu, S., Dias, S., Gaddini, A., Greacen, T., Ioannidis, E., Kluge, I., Krasnik, A., Lamkaddem, M., Lorant, V., Puigpinosi, R., Savary, A., Soares, J.J.F., Stankunas, A., Strassmayr, C., Wahlbeck, K., Weibel, M. and Bogic, M. (2011) Good Practice in Health Care for Migrants: Views and Experiences of Care Professionals in 16 European Countries. BMC Public Health, 11:187.

Propper, C. (2000) The Demand for Private Health Care in the UK. Journal of Health Economics, 19(6), 855-876.

Region Zealand (2015) Kapacitetsplan for fodterapi (November ed.) Denmark

Schaper, N.C., Van Netten, J.J., Apelqvist, J., Lipsky, B.A. and Bakker, K. (2017) Prevention and Management of Foot Problems in Diabetes: A Summary Guidance for Daily Practice 2015, Based on the IWGDF Guidance Documents. Diabetes Research and Clinical Practice, 124, 84-92

Sorts $\varnothing$, C., Green, A., Jensen, P. and Emneus, M. (2016) Societal Costs of Diabetes Mellitus in Denmark. Diabetic Medicine, 33(7), 877-885.

sundhed.dk (2015) Find behandler; Available at: https://www.sundhed.dk/findbehandler/?action=Search\&OrganizationTypeId=10\&regionid=0\&name. Accessed 11/05, 2015.

The Capital Region of Denmark (2013) Praksisplan for fodterapi 2013-2016. Copenhagen

The North Denmark Region (2016) Praksisplan 2016. Denmark

Wang, F. and Luo, W. (2005) Assessing Spatial and Nonspatial Factors for Healthcare Access:

Towards an Integrated Approach to Defining Health Professional Shortage Areas. Health and Place, 11(2),131-146.

(C) 2019 by the author(s). This article is an open access article distributed under the terms and conditions of the Creative Commons Attribution license (http://creativecommons.org/licenses/by/4.0/). 